\title{
Shear strength of aggregates compared with bulk soil of two haploxerolls from Chile
}

\author{
I. Fuentes*, O. Seguel, M. Casanova \\ Universidad de Chile, Facultad de Ciencias Agronómicas, Departamento de Ingeniería y Suelos. Santiago, Chile. "Corresponding \\ author: ignacio.fuentes.sanroman@gmail.com
}

\begin{abstract}
Shear strength of aggregates and the bulk soil matrix in two Haploxeroll of central Chile was assessed in order to determine: (1) the effect of previous tillage on shear parameters between aggregates and in the soil matrix and (2) the effects of structure development on differences between dry-wet mechanical parameters. Undisturbed soil cylinders and single aggregates (0-10 cm layer) were collected from untilled and conventionally tilled sites in the Santiago (STG) and Mapocho Soil Series (MPC). General soil properties and shear parameters were determined. The shear tests were conducted on confined and free-draining aggregates and on soil cores, equilibrated at field capacity and air-dried, to obtain data on cohesion and angle of internal friction in the samples. Dry aggregates from the tilled sites showed 40 and $70 \%$ greater cohesion compared to untilled sites in STG and MPC soils, respectively, associated with a decrease in coarse porosity in the STG soil and a decrease in organic matter in the MPC soil, thus reducing its friability. In air-dried condition, aggregates from untilled sites developed 6-7 fold strength compared with soil matrix and the difference increased (9-13 fold) in samples from tilled sites. Undisturbed soil cores showed higher friction values when air-dried ( $68^{\circ}$ in average, compared with $43^{\circ}$ in individual aggregates), but at $-33 \mathrm{kPa}$ water tension the tendency was reversed. The results of this study confirm that smaller differences between wet and dry behaviour are associated with better structural development and lower tillage intensity.
\end{abstract}

Keywords: Shear test, cohesion, internal friction angle, soil structure

\section{Introduction}

Soil mechanical behaviour, in general, cannot be considered an extrapolation of the mechanical behaviour of its isolated components, e.g. soil aggregates. The aggregates comprise a tortuous porous system with smaller pores occupied by water or air, depending on water status, supported by a skeleton of solid mineral and organic particles (Hillel, 1998). However, the soil matrix, being composed of many aggregates, includes coarser interaggregate macropores and finer intraaggregate micropores, which results in great continuity, promoting drainage and aeration of the system (Hillel, 1998).

The processes involved in aggregate formation are related mainly to soil shrinkage and swelling caused by drying and wetting seasonal cycles (Semmel et al., 1990), as well as biotic agents (Kay and Angers, 2002). The relevance of both mechanism depends on soil 
texture; for example, while in sandy soil the presence of biotic agents are relevant (but not wetting and drying cycles), in soil with more than $15 \%$ of clay the seasonal cycles induce swelling and shrinkage, being of great importance for structure processes (Barzegar et al., 1995).

The drying and wetting cycles rearrange the primary particles during structure formation, which increases the more negative pore water pressure during drying. Furthermore, this process reduces the diameter of the water menisci and increases their pulling forces, which results in smaller distances between particles, concentrating cement agents at contact points and promoting greater strength and stability (Horn and Baumgartl, 2002). Individual aggregate strength determines how internal friction and cohesion depend on the quantity of contact points or on the pressures that can be transmitted through each point (Horn, 1993). The maximum soil strength therefore depends on the number and intensity of drying and wetting cycles, while the aggregate strength itself is associated in particular with the number of contact points between the primary particles (Semmel et al., 1990). By other hand, the effective stress theory (Horn and Baulmgartl, 2002) points that under unsaturated conditions internal tensions in the samples (described by water potential) result in higher soil strength; however, by action of external loads, secondary coarse pores could be collapsed and the effective stresses will be increased because of the more pronounced pore water pressure, effects linked to the $\mathrm{X}$ factor which describes the water saturation of the system (Horn, 1993).

Shear tests, which can be used to determine the stability of soils and aggregates, quantify the cohesion and internal friction of the samples according to the Mohr-Coulomb law, which relates the shear strength to the normal stresses applied (Kézdi, 1980; Fredlund and Rahardjo, 1993). Comparing the shear strength of aggregates and the soil matrix, Hallet et al. (2000) demonstrated that the soil matrix is less resistant to soil deformation, due to the higher proportion of coarse and more continuous pores. The values of cohesion and angle of friction are reported to be greater for aggregates than for undisturbed soil or homogenized soil samples (Horn et al., 1995) because of the hierarchical arrangements of particles in many soil Orders, but this hierarchy could be lost in soils with very intensive use (Horn et al., 1995; Hallet et al., 2000; Blanco-Moure et al., 2012).

During tillage, besides normal loads that affect the size distribution of pores, shear stresses occur. Tangential stresses can exceed the shear strength of soil, decreasing its cohesion and increasing the angle of internal friction, as long as the load applied in a shear test (constant speed) does not exceed the aggregate strength state (Horn et al., 1995). However, once this strength is exceeded, the aggregates are destroyed and the number of contact points between individual particles increases. Consequently, the unit volume of the soil as well as the friction values are reduced and the cohesion is increased (Horn et al., 1995). On the other hand, an increase in pore water pressure, caused by higher water content, promotes a decrease in the cohesive forces by reducing the tension between soil particles and by dissolving the cement agents that bind them. Moreover, by lubricating the contact surface of particles, the friction between these is reduced (Horn, 1993; Gitau et al., 2006).

The structure hierarchy was previously assessed in a Mollisol from central Chile, relating the aggregate size and the mechanical strength (Seguel and Horn, 2006a); nevertheless, it is necessary to clarify the effects of structure development on differences between drywet mechanical parameters. We hypothesize that smaller differences between wet and dry behaviour are associated with better structural development and lower tillage intensity. With the perspective that farm management affects the quality/quantity of organic inputs, soil disturbance and biological activity, and thereby the processes of aggregate formation, the aim of this study was to examine the shear parameters of the soil matrix in relation to the shear parameters of individual aggregates, in order to determine the relationship between mechanical properties depending on soil water potential, soil use and soil structure. 


\section{Materials and Methods}

\subsection{Study site and soils}

The work was carried out at the Laboratory of Soil Physics at the Faculty of Agronomic Sciences, University of Chile, in 2009. Soil samples were taken randomly from the surface horizon $(0-10 \mathrm{~cm})$ of two Soil Series under low intervention and conventional tillage conditions (no-till, NT, and conventional tillage, CT, respectively, detailed below), in order to study the influence of tillage and organic matter content on mechanical aggregate stability and soil structural development. The surface horizon was chosen because is the more exposed soil material to the external conditions (climatic agents, inputs of organic matter, tillage if corresponds, etc.). The Soil Series assessed corresponded to Santiago and Mapocho (STG and MPC, respectively), both located in the Metropolitan Region of central Chile. The region has a warm temperate climate, with long-term mean annual precipitation of $366 \mathrm{~mm}$, most of which occurs between May and August, and mean monthly air temperature ranging from a high of $26^{\circ} \mathrm{C}$ in January to a low of $4^{\circ} \mathrm{C}$ in July (Uribe et al., 2012).

Soils belonging to the Santiago Soil Series (Entic Haploxeroll according to Soil Survey Staff, 2010) are of alluvial origin and are located in the position of an alluvial fan, while the Mapocho Soil Series (Fluventic Haploxeroll according to Soil Survey Staff, 2010) occupies ancient alluvial terraces with flat topography (CIREN, 1996). ). The NT site on the STG soil has granular to subangular blocky structure, with a natural meadow and no history of farming in the last 10 years, while the CT site has subangular blocky structure and has been farmed during the last 11 years. The NT site on the MPC soil has granular structure, with ornamental trees over 20 years, while the CT site is structureless (massive) to weak subangular blocky, and has been under conventional tillage during the last 12 years. Both Mapocho and Santiago series under $\mathrm{CT}$ are wheeled by tractors $(4-6 \mathrm{Mg}$ ) and are mouldboard plowed. Due to the depressed position in the landscape, the lower permeability and the absence of a stony substrate, a higher proportion of 2:1 clays can be expected in the Mapocho than in the Santiago Soil Series (Luzio, 1996).

A basic characterization of each soil and each management system was carried out, measuring texture (hydrometer), bulk density (core), particle density (pycnometer) and water retention curve (plate extractors), all according to Dane and Topp (2002), and organic matter content (Sadzawka et al., 2004). The water retention curve was determined by measuring the volumetric water content of soil at different tensions using cylinders of $5 \mathrm{~cm}$ height and $6 \mathrm{~cm}$ in diameter. The cores were subjected to tensions of 0.2 and $6 \mathrm{kPa}$ in a sand box and 30, 100 and $1500 \mathrm{kPa}$ in a pressure plate extractor until to reach the equilibrium. Based on Hartge and Horn (2009), the fast drainage pores (FDP, $>50 \mu \mathrm{m}$ ) were calculated as the difference between the volumetric water content at -0.2 and $-6 \mathrm{kPa}$; the slow drainage pores (SDP, $10-50 \mu \mathrm{m}$ ) were calculated as the difference between volumetric water content at -6 and $-33 \mathrm{kPa}$, and the available water pores (AWP, 0.2-10 $\mu \mathrm{m})$ was calculated as the difference between water retention at -33 and $-1500 \mathrm{kPa}$, the last one considered the permanent wilting point (PWP).

\subsection{Shear test}

For the shear tests, undisturbed soil samples were taken in cores of $7 \mathrm{~cm}$ diameter, $3 \mathrm{~cm}$ high, while the aggregates between 2 and $4 \mathrm{~cm}$ in diameter were selected by screening soil in a friable condition. The cores and individual aggregates were both equilibrated at field capacity $(-33 \mathrm{kPa})$ or air-dried in order to simulate winter-summer conditions and to contrast wet and dry soil behaviour.

Direct shear tests (Kézdi, 1980) were applied to confined cores and aggregates with free drainage and normal loads $\left(\sigma_{n}^{*}\right)$ ranging between $0-50 \mathrm{kPa}$ in aggregates and cores equilibrated at $-33 \mathrm{kPa}$ and $0-300$ $\mathrm{kPa}$ in aggregates and cores at air dried condition. Cohesion and angle of friction values were derived using the Mohr-Coulomb equation: 
$\tau=\mathrm{C}+\mathrm{o}_{\mathrm{n}}^{\prime} \tan \varphi$

where $\tau$ is shear strength, $\mathrm{C}$ is soil cohesion, $o_{n}^{*}$ the normal load and $\varphi$ the angle of internal friction. To obtain significance greater than $95 \%$ on the straight line of adjustment, 4-6 replicates were measured for each curve, totalizing about 40 samples for cores and 40 samples for aggregates.

Aggregates were confined in two PVC cores and fixed with paraffin wax, keeping both cores independent of one another in shear tests. Soil matrix samples were confined in metal cylinders $(1.5 \mathrm{~cm}$ high) for the same tests. In the design used, the friction generated between soil and cylinder walls was negligible. Aggregate equivalent diameter (De) was determined as the mean of aggregate diameter measured in three axes. The shear and normal stresses were obtained from the following equation:

$\mathrm{o}_{(\mathrm{x}-\mathrm{z})}=\mathrm{F} /\left(\pi(\mathrm{De} / 2)^{2}\right)$

where $o_{(x-z)}$ is the shear and normal stresses, $F$ the force applied to the sample and $D e$ the equivalent diameter of the aggregates. In soil matrix samples, a $D e$ value equal to core diameter was used.

\subsection{Statistical analysis}

A general characterization was made with three replicates per soil and use. For shear tests, the necessary number of samples (4-6) was tested to assess significant adjustment $(a \leq 0.05)$ of the Mohr-Coulomb equation.

Data on physical properties of aggregates and the soil matrix from each Soil Series were subjected to ANOVA, considering their different use and management. Finally, a comparison of the regression straight lines using a conditional addition of squares was made. This carries out involved analysis of variance to the adjustment lines, differentiating both the slopes and the intercepts with the y-axis in the various straight lines $(a \leq 0.05)$.

\section{Results and Discussion}

\subsection{General characteristics of soils}

Both the STG and MPC soils were of loamy texture (Table 1), with a greater amount of clay-sized particles under conventional tillage (CT). Comparing the same management, the STG soil tended to have a higher fraction of clay-sized particles than the MPC soil, although the differences were not statistically significant.

The organic matter (OM) content was lowest in the STG soil in both conventionally tilled and nontilled sites, but the non-tilled samples showed low bulk density, related to a low influence of external stresses and better structural stability. Consequently, the NT samples compared with CT samples had higher water availability and fewer fine pores (Table 2), which can be explained by the better structure and larger particle size, respectively (Osunbitan et al., 2005).

The untilled (NT) samples of the MPC soil showed a significant bigger OM content compared with the tilled samples (CT), presumably due to the accumulation of organic residues left by the trees in the NT site of MPC. In spite of soil aeration and oxidation of organic $\mathrm{C}$ promoted by tillage (Six et al., 2004) the OM content in MPC CT is in agreement with values of the soil Series according to CIREN (1996). Bulk density data showed the expected difference between management regimes, due to the high degree of stability and settlement of the non-tilled soil. In NT soil, colloidal organic particles could support the occlusion of pores (Caron et al., 1996), decreasing the coarse porosity and increasing the very fine porosity (Table 2). Moreover, the CT site on the MPC soil had been recently ploughed, although it was impossible to detect wheel tracks. All these factors resulted under CT samples generally having higher porosity and a lower distribution of wilting point porosity compared with NT samples. 
Table 1. Soil properties of the Santiago (STG) and Mapocho (MPC) soils under no tillage (NT) and conventional tillage (CT).

\begin{tabular}{|c|c|c|c|c|c|c|c|}
\hline \multirow{2}{*}{ Soil } & Clay & Sand & Silt & Organic matter & Bulk density & & Particle density \\
\hline & \multicolumn{3}{|c|}{ 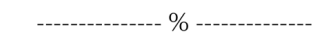 } & ---- $\mathrm{g} \mathrm{kg}^{-1}$---- & \multicolumn{3}{|c|}{ - } \\
\hline STG NT & $18.6 \pm 1.4$ & $36.1 \pm 0.3$ & $45.3 \pm 1.7$ & 0.364 & 1.29 & A & $2.53 \pm 0.14$ \\
\hline STG CT & $22.9 \pm 0.7$ & $34.6 \pm 1.2$ & $42.5 \pm 0.4$ & 0.370 & $1.53 \pm 0.09 \mathrm{~b}$ & B & $2.66 \pm 0.10$ \\
\hline MPC NT & $16.8 \pm 0.7$ & $42.9 \pm 1.5$ & $40.3 \pm 0.7$ & 0.793 b B & $1.45 \pm 0.08$ & B & $2.58 \pm 0.13$ \\
\hline MPC CT & $22.0 \pm 0.7$ & $34.0 \pm 0.3$ & $44.0 \pm 0.7$ & $0.387 \mathrm{a}$ & $1.33 \pm 0.07$ & A & $2.67 \pm 0.08$ \\
\hline
\end{tabular}

(a) NT: no tillage; CT: conventional tillage. (b) Different lowercase letters indicate statistically significant differences between managements for each Soil Series $(\alpha<0.05)$. Different capital letters indicate statistically significant differences between different Soil Series for each management $(\alpha<0.05)$.

Table 2. Pore size distribution in the Santiago (STG) and Mapocho (MPC) soils under no tillage (NT) and conventional tillage (CT)

\begin{tabular}{|c|c|c|c|c|c|}
\hline Soil & $\mathrm{FDP}^{(\mathrm{a})}$ & SDP & AWP & WPP & $\mathrm{TP}$ \\
\hline STG NT & $11.3 \pm 0.9 \mathrm{~B}^{(\mathrm{b})}$ & $6.1 \pm 0.5$ & $19.5 \pm 2.2 \mathrm{~b}$ & $11.2 \pm 0.0$ a $\mathrm{A}$ & $48.1 \pm 1.8$ \\
\hline STG CT & $10.7 \pm 0.4$ & $5.3 \pm 0.4$ & $12.0 \pm 2.6 \mathrm{a}$ & $16.8 \pm 0.5$ b B & $44.8 \pm 2.4 \mathrm{~A}$ \\
\hline MPC NT & $7.3 \pm 1.2 \mathrm{~A}$ & $6.0 \pm 1.3$ & $17.4 \pm 1.6$ & $17.8 \pm 0.4$ b B & $48.5 \pm 1.9$ \\
\hline MPC CT & $10.5 \pm 3.2$ & $7.2 \pm 1.5$ & $16.7 \pm 1.8$ & $15.6 \pm 0.1$ a $\mathrm{A}$ & $50.0 \pm 1.2 \mathrm{~B}$ \\
\hline
\end{tabular}

(a) FDP: Fast draining pores ( $>50 \mu \mathrm{m})$; SDP: Slow draining pores $(50-10 \mu \mathrm{m})$; AWP: Available water pores $(10-0.2 \mu \mathrm{m})$; WPP: Wilting point pores $(<0.2 \mu \mathrm{m})$; TP: Total porosity. (b) Different lowercase letters indicate statistically significant differences between managements for each Soil Series $(\alpha<0.05)$. Different capital letters indicate statistically significant differences between different Soil Series for each management $(\alpha<0.05)$.

The differing behaviour between the different uses for the STG and MPC soils, whereby non-tilled STG soil had lower bulk density than tilled while MPC soil did not show any differences between the different managements, may be related to their soil mineralogy (Barzegar et al., 1995). The 2:1 clay type in the Mapocho Soil Series induces greater shrinkage-swelling by drying-wetting, which may encourage pedoturbation and thus increase the translocation of materials and pore occlusion, leading to an increase in bulk density at the NT site (Gregory et al., 2010; Pathak et al., 2011). Therefore, when comparing the pore size distribution in both Soil Series for the same management regime, the
NT samples showed significantly higher fast draining porosity for STG than MPC soil, besides significantly reduced wilting point porosity. On the other hand, the NT samples from the STG soil had a higher wilting point porosity and lower total porosity than the NT samples from the MPC soil.

\subsection{Shear tests on confined, free-draining samples}

Statistical analyses revealed that cohesion of aggregates, air-dried and equilibrated at $-33 \mathrm{kPa}$, showed significant differences between soils, while friction did not differ between these (Table 3). 
Table 3. Cohesion and angle of internal friction of the Santiago (STG) and Mapocho (MPC) soils under no tillage (NT) and conventional tillage (CT).

\begin{tabular}{|c|c|c|c|c|c|c|}
\hline \multirow{2}{*}{ Sample } & $\mathrm{C}(\mathrm{kPa})^{(\mathrm{a})}$ & $\varphi\left({ }^{\circ}\right)$ & $\mathrm{C}(\mathrm{kPa})$ & $\varphi\left({ }^{0}\right)$ & & \multirow{2}{*}{$\begin{array}{c}\Delta \mathrm{C} \text { Dry - Moist } \\
(\mathrm{kPa})\end{array}$} \\
\hline & \multicolumn{2}{|c|}{---- air-dried ---- } & \multicolumn{3}{|c|}{--- $33 \mathrm{kPa}$----- } & \\
\hline & \multicolumn{5}{|c|}{ Aggregates } & \\
\hline STG NT & 106.2 a $A^{*(b)}$ & $37.5 *$ & $8.3 \mathrm{~b}$ & 44.9 & & 98 \\
\hline STG CT & $148.1 \mathrm{~b} \mathrm{~A} *$ & 39.5 & $3.5 \mathrm{a} \mathrm{A}$ & 52.0 & * & 145 \\
\hline MPC NT & $144.2 \quad \mathrm{~B} *$ & 44.4 & $8.4 \mathrm{a}$ & 39.5 & & 136 \\
\hline \multirow[t]{2}{*}{ MPC CT } & $251.8 \quad$ B * & $51.7 *$ & $10.1 \mathrm{~b} \mathrm{~B}$ & 45.9 & * & 242 \\
\hline & \multicolumn{5}{|c|}{ Soil matrix } & \\
\hline STG NT & $19.3 \mathrm{~b} \mathrm{~A}$ & $70.9 \quad \mathrm{~B}$ & 9.5 & 38.9 & & 9.8 \\
\hline STG CT & 11.0 a $\mathrm{A}$ & 68.5 & 10.9 & 34.0 & & 0.1 \\
\hline MPC NT & 20.2 a B & 61.8 a A & 8.9 & 37.6 & & 11.3 \\
\hline MPC CT & 28.3 b B & $69.3 \mathrm{~b}$ & 11.5 & 34.1 & & 16.8 \\
\hline
\end{tabular}

(a) C: Soil cohesion; $\varphi$ : Internal friction; $\Delta \mathrm{C}$ : Difference between air-dried and -33 kPa. (b) Different lowercase letters indicate statistically significant differences between managements for each Soil Series $(a<0.05)$. Different capital letters indicate statistically significant differences between Soil Series for each management $(a<0.05)$. Asterisk $(*)$ indicates significant difference between aggregates and soil matrix for the same soil and use.

Air-dried aggregates of tilled STG soil showed higher cohesion that those under no till. In this case, both the highest clay content and the external tensions exerted by tillage presumably increased the cohesion of the soil by increasing the number and force of contact points between particles, reducing the pore and crack sizes that constitute the failure planes in the shear test (Horn et al., 1995; Horn and Baumgartl, 2002; Munkholm et al., 2002). The corresponding results for the MPC soil showed no significant differences because of a high variation in the data.

At $-33 \mathrm{kPa}$, the tilled STG soil had the lowest cohesion, with the deteriorated structure indicating that this soil had supported many tillage events and had been subjected to high external loads. These had apparently rearranged the particles to denser configurations, since at high pore water pressures the CT samples of STG soil showed structural deterioration, denoted by the low shear strength of their aggregates (Stock and Downes, 2008). At -33 kPa the MPC soil maintained the tendency shown for air-dried aggregates, with higher cohesion under conventional tillage.

In both management regimes (NT and $\mathrm{CT}$ ) and at both pore water pressures tested, the MPC soil showed greater cohesion than the STG soil at slightly lower clay content. This may be associated with the increased structural stability of the MPC aggregates resulting from its higher OM content and 2:1 clay dominance (Besoaín and González, 1978) and the higher number of contact points between particles, denoted by the lower amount of coarse pores and higher amount of fine pores (Horn and Baumgartl, 2002).

In soil matrix samples, the higher cohesion of dry CT samples of MPC soil is likely to be associated with the effect of external loads, granulometry and a lower OM content, decreasing soil friability (Watts and Dexter, 1998; Abid and Lal, 2009). In STG soil there was higher cohesion under no tillage, although these samples had a coarser texture. 
As a consequence of less intense stress application, even the more sandy structure had become rigid (i.e. these soils had higher structural stability) compared with the strength of the tilled soil, as was demonstrated by Daraghmeh et al. (2009) in a sandy loam soil under reduced tillage compared with the same soil under conventional tillage. The MPC soil samples equilibrated at $-33 \mathrm{kPa}$ did not show significant differences in either cohesion or angle of friction. This can be explained by the effect of water saturation linked to the less intense menisci forces, resulting in a higher mobility and lubrication effect (Gitau et al., 2006).

\subsection{The role of the OM on structural stability}

The comparison between parameters obtained from fitting lines for aggregates and bulk soil matrix showed that the air-dried soil cores had significantly lower cohesion values than individual aggregates, while at $-33 \mathrm{kPa}$ the values for bulk soil matrix and aggregates were similar.

Since intraaggregate porosity is related to higher tortuosity, lower pore diameter and continuity, it generates higher strength (Seguel and Horn, 2006a), while interaggregate porosity has the opposite characteristics, associated with the hierarchy of aggregation (Hallet et al., 2000). Thus, macroaggregates present abundant macropores, fault planes and weakness points that promote a lower strength in soil matrix samples than in individual aggregates, which have a greater array of links and contact points. This has been confirmed in other studies (Hallet et al., 1995; Horn et al., 1995; Munkholm et al., 2002), which report an inverse correlation between the content of macropores and the tensile strength.

Soil cores of Mapocho soil under no tillage, which had the highest OM content, showed a low strength in dry condition. This result can be extrapolated to the other treatments because there is a variation in the role and distribution of the different fractions of soil OM, which may help to explain the difference in physical behaviour between aggregates and soil matrix (Tisdall and Oades,
1982; Smucker et al., 2007). Macroaggregates have 15 to $35 \%$ more organic carbon than microaggregates in untilled soils (Puget et al., 2005) because, in natural conditions, slightly decomposed plant residues enter the soil system and occupy the interaggregate pore space. This situation changes when the soil is ploughed, with the $\mathrm{OC}$ then depends on clay mineralogy, form of tillage and particle size distribution (Six et al., 2004).

The presence of mineralizable $\mathrm{OM}$ induces an increase in microbial biomass, which promotes the secretion of polysaccharides and other compounds that are associated directly with the mineral particles (Tisdall and Oades, 1982; Waters and Oades, 1991). The excreted polysaccharides can exist as fibrous or granular material and come to be closely related to the mineral fraction as the soil dries, enhancing the strength by inducing a great force between the links and by promoting a higher wetting angle, higher hydrophobia and, in consequence, a lower wetting rate (Chenu and Cosentino, 2011). This allows entrapped air to escape without the development of high stresses in soil samples (Le Bissonnais and Arrouays, 1997).

The dynamics of this mineralizable $\mathrm{OM}$ affect the intensity and duration of the effect on the aggregate stability (Chenu and Cosentino, 2011). After the consumption of the more labile portion of organic debris, the more resistant structural materials are concentrated as occluded particles within soil aggregates, generating an abundance of empty spaces within aggregates that could be in the range of 0.1 to $30 \mu \mathrm{m}$ in diameter. At advanced stages of mineralization, the sites of plant decomposition may form fault zones of low strength in the matrix, leading to smaller resistance and encouraging aggregation (Kay and Angers, 2002). In this work we assumed a negligible hydrophobic effect of $\mathrm{OM}$ and an effect of root and organic debris integrated into the pore size distribution, contact points between solid particles and the resulting bulk density of the soil system.

Degradation of organic materials ultimately leads to their stabilization in the soil by transformation into recalcitrant 
compounds closely associated with the mineral phase (Urbanek et al., 2011). The recalcitrant nature of these compounds may be partially explained by the physical protection from attack by microorganisms as a result of their adsorption or location in pores that are too small to be accessible (Kay and Angers, 2002; Six et al., 2004). These fractions are found in higher proportions in aggregates than in the soil matrix and, by reducing the cracks and pores that act as fault planes, can promote greater strength in aggregates (Caron et al., 1996). This is confirmed by our data for the air-dried samples. Aggregates from untilled sites showed between 5- and 7-fold greater cohesion than the soil matrix (Table 3). However, the role of previous loads in the rearrangement of particles and the reduction in pore size dominated in some cases, reducing the effect of organic materials at low pore water pressures. This is in agreement with previous results of Horn et al. (2007), who highlighted the importance of bulk density in the mechanical strength for a soil with a previous known management, and was demonstrated in this work in the soils under tillage, where the cohesion of aggregates was 8- to 14-fold higher than the cohesion of the soil matrix.

\subsection{The role of wetting and drying cycles on structural stability}

Soil strength increases as long as the decrease in the negative pore water pressure exceeds the decrease in the $\mathrm{X}$ factor of the effective stress equation, and this depends on the degree of saturation of soil (Horn, 1993). However, due to the pore size distribution within aggregates, the water content in aggregates is higher than that in the soil matrix over a wide range of the water retention curve (Horn and Smucker, 2005), allowing better development of internal stresses and resulting in higher strength in individual aggregates than in the soil matrix (Hallet et al., 2000).

Regarding the angle of internal friction, the soil matrix showed very high values in dry conditions compared with the equilibrium at $-33 \mathrm{kPa}$, which is consistent with results obtained by Zhang and Hartge (1995).
Comparing individual aggregates and the matrix, the main differences were seen for air-dried samples, where soil cores had a higher angle of friction than individual aggregates. This is because the friction in soil cores corresponds to that generated between aggregates. On other hand, at $-33 \mathrm{kPa}$ aggregates had a higher friction than the soil matrix. Thus, while in air-dried samples friction becomes dependent on microaggregation and the shape and arrangement of elementary particles and soil aggregation, in samples equilibrated at $-33 \mathrm{kPa}$ the water potential limits the effect of microaggregation of the primary particles and of the structure and lubricates the contact areas. Hence, in general, the angle of internal friction was slightly lower in moist conditions than in dry conditions, although the greater friction in aggregates at $-33 \mathrm{kPa}$ may be associated with denser arrangements of these compared with soil cores (Lal and Shukla, 2004).

Soil cores equilibrated at $-33 \mathrm{kPa}$ showed the pattern previously reported by Horn (1993) at low internal tensions, where the angle of friction was highest in aggregates, followed by the bulk soil matrix and finally homogenized soil. The homogenized soil was similar to the soil cores taken under conventional tillage (CT).

As shown in dry samples, the Santiago soil under tillage had suffered structural damage since, despite the higher bulk density and particle rearrangement by traffic, it had lower friction than the corresponding nontilled STG soil. The Mapocho soil, on the other hand, had coarser granulometry, a higher OM matter content and an absence of external loads on the non-tilled soil, all factors that promote higher friability in soil cores, resulting in a lower internal friction compared with the corresponding conventionally tilled MPC soil.

In general, non-tilled samples showed less variation between dry and wet cohesion $(\Delta \mathrm{C}$, Table 3$)$ as a consequence of greater structural stability (Semmel et al., 1990; Stock and Downes, 2008). In the NT samples from the Mapocho soil, this result may be associated with a higher OM content, which during wetting of the 
aggregates would prevent the development of stresses by trapped air compression in the intraaggregate pore space (Le Bissonnais and Arrouays, 1997). In this regard, the OM contributes to stability by reducing the rate of wetting by its increased hydrophobicity (Caron et al., 1996).

In the Santiago soil under tillage, the largest difference in cohesion at both pore water pressures was due to the settlement of the soil samples caused by traffic, since the applied loads imparted a high strength to dried samples by reducing the size of cracks and natural fault planes, as was demonstrated by Seguel and Orellana (2008) in Ultisols from southern Chile. Furthermore, the strength recovered after ploughing by the effect of age hardening is not comparable to the natural arrangement, which results from repeated cycles of drying and wetting at low intensities and in balance with the environment (Semmel et al., 1990).

It is important to consider the role of amount, size distribution and continuity of pores in the physical resilience of soil samples. Some samples, which present a high hydraulic conductivity due to great pore diameter and continuity, respond with small changes in pore water pressures during compression and shear tests due to fast water drainage (Peth and Horn, 2006), thereby, increasing the stability as long as the load applied does not exceed the brittle behaviour of soil samples (Bohne and Lessing, 1988). Disturbed soil samples and aggregates, which have a lower pore continuity and lower pore diameter than bulk soil samples, display higher changes in pore water pressure due to external loads, generating a lower stability and a larger differential in cohesion (Seguel and Horn, 2006b). Unfortunately, in this work the pore water pressure changes and the pore continuity were not assessed.

The difference in cohesion between the dry and wet condition $(\Delta C)$ of aggregates was higher in MPC than in STG soil under the same management, as a result of the high cohesion of the MPC soil in dry conditions. This could be explained by its mineralogy (higher
2:1 clay content than STG) and the heterogeneity in its particle size distribution, which generates a greater number of contact points between particles (Horn and Baumgartl, 2002).

This difference in wet and dry behaviour becomes important when the potential for agriculture is being evaluated, because soils with a lower structural stability, either by deterioration associated with tillage and excessive traffic or by poorly developed structure, display greater differences in mechanical behaviour between wet and dry conditions (Stock and Downes, 2008). Thus, at high water contents, this kind of soil will behave in a plastic way and at low pore water pressures it will show excessive resistance. On the other hand, well-structured soils, with smaller differences in mechanical behaviour depending on the internal tensions, have a greater friability, with a marked inverse dependence between aggregate size and tensile strength. With tillage, such soils will show a better potential for disaggregation without altering the microaggregation, because of the increased strength in smaller aggregates (Hallet et al., 2000).

Regarding the difference between dry and moist cohesion $(\Delta C)$ in soil cores, the STG soil under tillage showed the lowest difference, associated with its low cohesion in dry conditions, so the dry and moist behaviour was similar owing to the structural deterioration. In MPC soil the behaviour was as expected from the higher structural stability of NT soil cores.

When the ratio between cohesion of aggregates and cohesion of soil matrix from air-dried samples was fitted for pores with diameter 0.2-10 $\mu \mathrm{m}$ (available water porosity), an inverse relationship was obtained (Figure 1).

According to this inverse correlation, the cohesion of the soil matrix became more similar to that of aggregates as the distribution of pores of small diameter increased, in this case in the range of available water. These can be considered similar to the intraaggregate 
pores. Thus, the finer the pore distribution of a soil, the smaller the fault planes, the closer the situation is to the final stage of smallest entropy, the more homogeneous the pores (as the lower structural development is) and the higher the similarity between the mechanical behaviour of the soil matrix and individual aggregates (Seguel and Orellana, 2008; Seguel and Horn, 2006b).

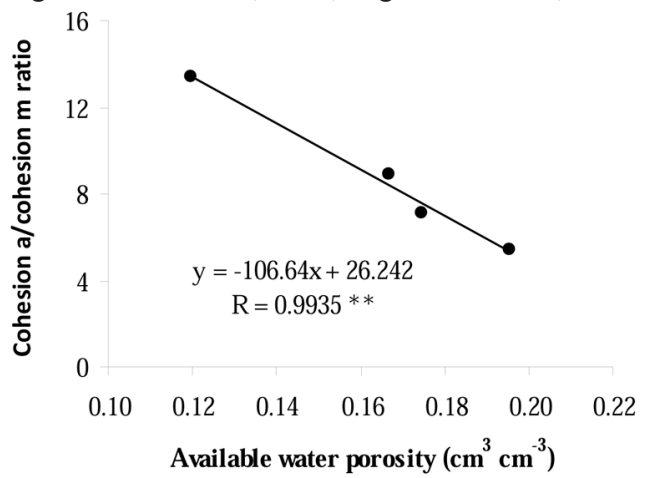

Figure 1. Dependence of aggregate (a) and soil matrix $(\mathrm{m})$ cohesion ratio on available water porosity (expressed as the proportion of pores between 0.2$10 \mu \mathrm{m})$. Each point represents an air-dried sample of an STG or MPC soil under a particular use. ** significance at $99 \%$.

Finally, there was a direct linear relationship between cohesion and angle of internal friction of dry aggregates, but at $-33 \mathrm{kPa}$ the relationship in aggregates was the inverse of that in the soil matrix (Figure 2).

The direct relationship between cohesion and angle of internal friction in air-dried aggregates (Figure 2a) can be attributed to the internal arrangement of microaggregates. At low pore water pressures, high cohesion and increased friction are induced by the higher number of contact points between aggregates (Fredlund and Rahardjo, 1993). In contrast, the inverse relationship of friction and cohesion in samples at field capacity (Figure 2b) is dependent on the size and shape of soil particles, where particles that promote higher cohesion (e.g. fine particles) are associated with a lower friction (planar shape of clay particles) in this case. This behaviour is also due to pressures higher than the precompaction strength during the shear test promoting the rearrangement of particles with the decrease in angle of friction (Horn et al., 1995).



Figure 2. Relationship between cohesion and angle of internal friction in aggregates and soil cores. a) Airdried samples. b) Samples equilibrated at $-33 \mathrm{kPa}$. Each point represents a significant value obtained for Mohr-Coulumb adjustment lines of shear data for soil cores and aggregates belonging to two soils under two managements (single data). Significance at $95 \%$ $(*)$ and $99 \%(* *)$.

\section{Conclusions}

The shear strength of the soils tested proved to be dependent on both internal tensions and external stresses. In general, in air-dried samples the strength of aggregates was considerably greater than that of 
soil cores due to the smaller size and number of pores and cracks, which are natural fault planes and generate less cohesion. On the other hand, bulk soil samples had higher angle of internal friction because during the shear tests the single aggregates within the structured bulk soil must be moved above each other. At -33 $\mathrm{kPa}$ the difference in cohesion between soil cores and single aggregates decreased significantly because of lubrication by water, while the angle of internal friction at this pore water pressure remained greater for aggregates than for the soil matrix.

Regarding soil management, in general non-tilled soils were more friable than the corresponding tilled soils subjected to previous loads, and showed smaller differences in mechanical behaviour at different pore water pressures. Overall, soils with better structural development had smaller differences in mechanical parameters between wet and dry conditions.

\section{References}

Abid, M, Lal, R. 2009. Tillage and drainage impact on soil quality: II. Tensile strength of aggregates, moisture retention and water infiltration. Soil Till. Res. 103, 364-372.

Barzegar, A.R., Rengasamy, P., Oades, J.M. 1995. Effects of clay type and rate of wetting on the mellowing of compacted soils. Geoderma. 68, 39-49.

Besoaín, E., González, S. 1978. Relaciones mineralógicas y genéticas en algunos suelos representativos de la región central y central sur de Chile. In: Actas I Simposio Nacional de la Ciencia del Suelo, Departamento de Suelos, Facultad de Agronomía, Universidad de Concepción, pp: 1-37.

Blanco-Moure, N., Angurel, L. A., Moret-Fernández, D., López, M. V. 2012. Tensile strength and organic carbon of soil aggregates under long-term no tillage in semiarid Aragon (NE Spain). Geoderma. 189190, 423-430.
Bohne, H., Lessing, R. 1988. Stability of clay aggregates as a function of water regimes. In: J. Drescher, R. Horn, M. de Boodt (eds). Impact of water and external forces on soil structure. Catene Supplement 11, Cremlingen, Germany, 29-34.

Caron, J., Espindola, C.R., Angers, D.A. 1996. Soil structural stability during rapid wetting: Influence of land use on some aggregate properties. Soil Sci. Soc. Am. J. 60, 901-908.

Chenu, C., Cosentino, D. 2011. Microbial regulation of soil structural dynamics. In: K. Ritz, I. Young (eds). The architecture and biology of soils. Life in inner space. CABI, London, pp: 37-70.

CIREN. 1996. Estudio Agrológico. Región Metropolitana. Descripciones de suelos, materiales y símbolos. Publicación Miscelánea $N^{\circ} 115,414$ p.

Dane, J.H., Topp, G.C. 2002. Methods of Soil Analysis, Part 4: Physical Methods. Soil Sci. Soc. of Am., Inc., Madison, WI, USA, 1692 p.

Daraghmeh, O.A., Jensen, J.R., Petersen, C.T. 2009. Soil structure stability under conventional and reduced tillage in a sandy loam. Geoderma. 150, 64-71.

Fredlund, D.G., Rahardjo, H. 1993. Soil Mechanics for Unsaturated Soils. John Wiley \& Sons, New York, USA, 517 p.

Gitau, A.N., Gumbe, L.O., Biamah, E.K. 2006. Influence of soil water on stress-strain behavior of a compacting soil in semi-arid Kenya. Soil Till. Res. 89, 144-154.

Gregory, A.S., Webster, C.P., Watts, C.W., Whalley, W.R., Macleod, C.J., Joynes, A., Papadopoulos, A., Haygarth, P.M., Binley, A., Humphreys, M. W., Turner, L.B., Spot, L., Matthews, G.P. 2010. Soil Management and Grass Species Effects on the Hydraulic Properties of Shrinking Soils. Soil Sci. Soc. Am. J. 74, 753-761. 
Hallet, P.D., Dexter, A.R., Seville, J. 1995. The application of fracture mechanics to crack propagation in dry soil. Eur. J. Soil Sci. 46, 591599.

Hallet, P.D., Dexter, A.R., Bird, N., Seville, J. 2000. Scaling of the structure and strength of soil aggregates. In: R. Horn, J. van den Akker, J. Arvindsson (eds). Subsoil compaction. Distribution, processes and consequences. Advances in Geoecology 32. IUSS, pp: 22-31.

Hartge, K.H. 1988. The reference base for compaction state of soils. In: J. Drescher, R. Horn, M. de Boodt (eds). Impact of water and external forces in soil structure. Catena Supplement 11. Catena Verlag, Reiskirchen, Germany, pp: 73-77.

Hartge, K., Horn, R. 2009. Die physikalische Untersuchung von Böden. E. Schweizerbart'sche Verlagsbuchhandlung. Stuttgart, Germany, 178 p.

Hillel, D. 1998. Environmental Soil Physics. Academic Press. Boston, 771 p.

Horn, R. 1993. Mechanical properties of structured unsaturated soils. Soil Technol. 6, 47-75.

Horn, R., Baumgartl, T., Kayser, R., Baasch, S. 1995. Effect of aggregate strength on strength and stress distribution in structured soils. In: K. Hartge, B. Steward (eds). Soil structure. Its development and function. Lewis Publishers. Boca Raton, Florida, pp: 31-52.

Horn, R., Baumgartl, T. 2002. Dynamic properties of soils. In: A. W. Warrick (ed). Soil physics companion. CRC Press. Boca Raton, Florida, pp: 17-43.

Horn, R., Smucker, A. 2005. Structure formation and its consequences for gas and water transport in unsaturated arable and forest soils. Soil Till. Res. 82, 5-14.
Horn, R., Hartge, K. R., Bachmann, J., Kirkham, M.B. 2007. Mechanical stresses in soils assessed from bulk-density and penetration-resistance data sets. Soil Sci. Soc. Am. J. 71, 1455-1459.

Kay, B.D., Angers, D.A. 2002. Soil structure. In: A. W. Warrick (ed). Soil Physics Co mpanion. CRC Press. Boca Raton, Florida, pp: 249-283.

Kézdi, A. 1980. Handbook of Soil Mechanics. Vol. 2. Soil testing. Elsevier Scientific Publishing Company. New York, 258 p.

Lal, R., Shukla, M.K. 2004. Soil solids. In: M. Dekker (ed). Principles of Soil Physics. Part II, Soil Mechanics. New York, pp: 29-85.

Le Bissonnais, Y., Arrouays, D. 1997. Aggregate stability and assessment of soil crustability and erodability: Application to humic loamy soils with various organic carbon contents. Eur. J. Soil Sci. 48, 39-48.

Luzio, W. 1996. Clasificación Taxonómica de los Suelos de la Región Metropolitana y VI Región (Keys to Soil Taxonomy, SCS, USDA, 1994). Universidad de Chile, Facultad de Ciencias Agronómicas, Santiago, 21 p.

Munkholm, L., Schjonning, P., Kay, B.D. 2002. Tensile strength of soil cores in relation to aggregate strength, soil fragmentation and pore characteristics. Soil Till. Res. 64, 125-135.

Pathak, P., Wani, S.P., Rao Sudi, R. 2011. Long-term effects of management systems on crop yield and soil physical properties of semi-arid tropics of Vertisols. Agricultural Sciences. 2, 435-442.

Peth, S., Horn, R. 2006. The mechanical behavior of structured and homogenized soil under repeated loading. J. Plant Nutr. Soil Sci. 169, 401-410. 
Puget, P., Lal, R., Izaurralde, M., Post, M., Owens, L. 2005. Stock and distribution of total and cornderived soil organic carbon in aggregate and primary particle fractions for different land use and soil management practices. Soil Sci. 170, 256-279.

Sadzawka, A., Carrasco, M.A., Grez, R., Mora, M.L. 2004. Métodos de análisis recomendados para los suelos chilenos. Comisión de Normalización y Acreditación, Sociedad Chilena de la Ciencia del Suelo, Santiago, Chile, 113 p.

Seguel, O., Horn, R. 2006a. Structure properties and pore dynamics in aggregate beds due to wetting - drying cycles. J. Plant Nutr. Soil Sci. 169, 221-232.

Seguel, O., Horn, R. 2006b. Strength regain in soil aggregate beds by swelling and shrinkage. Int. Agrophysics. 20, 161-172.

Seguel, O., Orellana, I. 2008. Relación entre las propiedades mecánicas de suelos y los procesos de génesis e intensidad de uso. Agro Sur. 38, 82-92.

Semmel, H., Horn, H., Hell, U., Dexter, A., Osmond, G., Schulze, E. 1990. The dynamics of soil aggregate formation and the effect on soil physical properties. Soil Technol. 3, 113-129.

Six, J., Bossuyt, H., Degryze, S., Denef, K. 2004. A history of research on the link between (micro) aggregates, soil biota, and soil organic matter dynamics. Soil Till. Res. 79, 7-31.

Smucker, A., Park, E.J., Dörner, J., Horn, R. 2007. Soil micropore development and contributions to soluble carbon transport within macroaggregates. Vadoze Zone J. 6(2), 282-290.

Soil Survey Staff. 2010. Keys to Soil Taxonomy, 11th ed. USDA-Natural Resources Conservation Service, Washington, DC, $333 \mathrm{p}$.
Soil Survey Staff. 2010. Keys to Soil Taxonomy, 11th ed. USDA-Natural Resources Conservation Service, Washington, DC, 333 p.

Stock, O., Downes, N. 2008. Effects of additions of organic matter on the penetration resistance of glacial till for the entire water tension range. Soil Till. Res. 99, 191-201.

Tisdall, J.M., Oades, J.M. 1982. Organic matter and water-stable aggregates in soils. J. Soil Sci. 33, 141-163.

Urbanek, E., Smucker, A.J.M., Horn, R. 2011. Total and fresh organic carbon distribution in aggregate size classes and single aggregate regions using natural 13C/12C tracer. Geoderma. 164, 164-171.

Uribe, J. M., Cabrera, R., de la Fuente, A., Paneque, M. 2012. Atlas Bioclimático de Chile. Universidad de Chile. Santiago, Chile, 232 p.

Waters, A.G., Oades, J.M. 1991. Organic matter in water-stable aggregates. In: W. S. Wilson (ed). Advances in soil organic matter research. The impact on agriculture and the environment. Royal Soc. Chem., Cambridge, pp: 163-174.

Watts, C.W., Dexter, A.R. 1998. Soil friability: theory, measurement and the effects of management and organic carbon content. Eur. J. Soil Sci. 49, 73-84.

Zhang, H.Q., Hartge, K.H. 1995. Mechanical properties of soils as influenced by the incorporation of organic matter. In: K. Hartge, B. Steward (eds). Soil Structure, its development and function. Lewis Publishers, Boca Raton, Florida, pp: $93-$ 108. 